\title{
Diagnosis of primary human herpesvirus 6 and 7 infections in febrile infants by polymerase chain reaction
}

Duncan A Clark, I Michael Kidd, Kathryn E Collingham, Michael Tarlow, Titi Ayeni, Andrew Riordan, Paul D Griffiths, Vincent C Emery, Deenan Pillay

\begin{abstract}
Primary human herpesvirus 6 (HHV-6) and 7 (HHV-7) infections were identified in febrile children by qualitative and quantitative polymerase chain reaction (PCR) assays. Diagnosis was based on the differential detection of viral DNA in peripheral blood mononuclear cells (PBMC), but not in saliva. Six of 41 febrile infants, but none of seven non-febrile controls, were identified with primary infections (three HHV-6, three HHV-7). These children had significantly higher viral loads in PBMC (HHV-6, median 24213 genomes $/ 10^{6}$ PBMC; HHV-7, median 6040000 genomes $/ 10^{6}$ PBMC) than DNAaemic, saliva PCR positive children (HHV-6, median 1606 genomes $/ 10^{6}$ PBMC, p $<0.01$; HHV-7, median 7089 genomes $10^{6}$ PBMC, $\left.p<0.05\right)$. Viral DNA was detected in serum by PCR in only $50 \%$ of primary infections. All three children with primary HHV-7 infection had febrile convulsions. Thus PCR, including quantitative assays, may identify primary HHV-6 and HHV-7 infections when an appropriate combination of clinical specimens is used.
\end{abstract}

(Arch Dis Child 1997;77:42-45)

Keywords: HHV-6; HHV-7; febrile convulsions; polymerase chain reaction

Regional Virus Laboratory, Public Health Laboratory, Heartlands Hospital, Birmingham

K E Collingham D Pillay

Department of Infection, University of Birmingham M Tarlow

Department of Paediatrics, Heartlands Hospital, Birmingham

T Ayeni

A Riordan

Correspondence to: Dr Vincent C Emery, Department of Virology, Royal Free Hospital Schoo of Medicine, Rowland Hill Street, Hampstead, London NW3 $2 \mathrm{PF}$.

Accepted 16 April 1997

Human herpesvirus 6 (HHV-6) and 7 (HHV-7) are ubiquitous lymphotropic $\beta$ herpesviruses that infect most persons in childhood. ${ }^{1-3}$ Primary infection with HHV-6 is associated with febrile illness, ${ }^{4}$ including exanthem subitum, ${ }^{5}$ with convulsive seizures recognised as a common complication. ${ }^{4}$ To date, the clinical features of primary HHV-7 infection are less well defined, although the virus has also been shown to cause exanthem subitum. ${ }^{6}$ Therefore it is important to consider these two viruses in the differential diagnosis of febrile illness in young children. Laboratory diagnoses of active HHV-6 and HHV-7 infections have most commonly used virus isolation from peripheral blood or documented seroconversion/rise in antibody titre. ${ }^{4-8}$ Drawbacks to these approaches include the length of time to reach a laboratory diagnosis. For virus isolation, mitogen stimulated umbilical cord blood mononuclear cells are required for cocultivation with the test sample since they are permis- sive for HHV-6 and HHV-7 infection. A drawback to serological diagnosis of infection is the need to collect both acute and convalescent serum samples.

Polymerase chain reaction (PCR) provides an alternative technique to identify viral infections. Since HHV-6 and HHV-7 persist in the host following primary infection, PCR methods which can identify clinically relevant viral replication are required. The detection of HHV-6 DNA in serum or plasma by PCR has been used as a marker for active infection in blood. ${ }^{910}$ In our study, however, a preliminary diagnosis of primary infection is based on the detection by PCR of viral DNA in peripheral blood mononuclear cells (PBMC), but not saliva. In children with exanthem subitum, a delay in the detection of HHV-6 or HHV-7 DNA in saliva by PCR has been reported in comparison to detection of viral DNA in blood. ${ }^{11}{ }^{12}$ Further, we used quantitative PCR (QPCR) to determine the actual number of viral genomes (viral load) in PBMC. Values obtained by such a measurement are likely to vary depending on whether they reflect persistence in normal individuals or primary infection or episodes of reactivation.

\section{Methods}

PATIENTS

Children aged from 6 to 36 months presenting to the accident and emergency and paediatric departments, Birmingham Heartlands Hospi- tal, with an acute febrile illness or a febrile convulsion were recruited between July 1995 and February 1996. The study was approved by Birmingham Heartlands Hospital ethics committee and written consent was obtained for all children through their parents or guardians. Children in the same age range attending the paediatric outpatient clinic or for routine surgery, with clinical conditions that were neither acute, infectious, nor febrile were recruited as controls. A full history and examination was undertaken, usually including full blood count and, where appropriate, blood and urine cultures and lumbar punctures.

\section{PREPARATION OF CLINICAL SAMPLES}

PBMC were obtained from $5 \mathrm{ml}$ EDTA blood samples by density centrifugation (Histopaque, Sigma Diagnostics, Poole) and DNA extracted from $10^{6}$ PBMC using a QIAamp blood kit (Qiagen, Dorking). Sera were collected from clotted blood samples. Saliva was obtained by 
rubbing the gums with a custom made toothbrush-like swab (Malvern Medical Developments, Worcester) and subsequent elution with phosphate buffered saline $(200 \mu \mathrm{l})$. All samples were stored at $-70^{\circ} \mathrm{C}$ until use.

\section{ANALYSIS OF CLINICAL SAMPLES BY QUALITATIVE} PCR

The nested PCR assays have been described previously for both HHV $-6^{13}{ }^{14}$ and HHV $-7 .^{15}$ For PBMC DNA, 100 ng were tested; for saliva, $30 \mu$ were overlaid with mineral oil, steamed for 10 minutes, and PCR reaction mixture added through the oil layer. The serum PCR assay was based on the method of Whitby et al. ${ }^{16}$ Briefly, serum was added to an equal volume of water, steamed for 10 minutes, centrifuged at $13000 \mathrm{~g}$ for 10 minutes, and $10 \mu \mathrm{l}$ supernatant tested.

ANALYSIS OF CLINICAL SAMPLES BY QPCR The HHV-6 and HHV-7 quantitative competitive PCR assays have been described previously. ${ }^{14}{ }^{15}$ Both assays have a broad dynamic range with a threshold of quantification estimated at $<10$ viral genomes.

SEROLOGY

IgG antibodies to HHV-6 and HHV-7 were determined by indirect immunofluorescence assays using HHV-6 variant B infected MOLT-3 cells and HHV-7 infected SUP-T1 cells, respectively, as antigen. Sera were screened at a 1:10 dilution.

\section{Results}

PATIENT POPULATION AND SAMPLES

Forty eight children were entered into the study: 29 with febrile convulsions, 12 with febrile episodes without convulsions (41 cases in total), and seven controls. The median ages in the cases and controls were similar at 13 months (range 6 to 36 ) and 11 months (range 4 to 31 ), respectively. The cases presented a mean of 2.05 days following onset of symptoms, with a mean temperature of $38.6^{\circ} \mathrm{C}$. Thirteen cases had additional respiratory tract symptoms, seven had rashes, eight had inflamed ear drums, and seven had diarrhoea or vomiting or both. Serum was available from all cases and controls. PBMC were not available from eight cases and saliva from two controls.

PREVALENCES OF HHV-6 AND HHV-7 IN CASES AND CONTROLS

There was no statistical difference in the prevalence of the two viruses in the cases compared to the controls by either PCR in blood and saliva or antibody status (Fisher's exact test) (table 1). For both HHV-6 and HHV-7, the median age of the seropositive group was significantly greater than that of the seronegative group (HHV-6, median age in seropositive children 14.0 months $v 7.0$ months in the seronegative children, $\mathrm{p}<0.0001 ; \mathrm{HHV}-7$, 15.0 months $v 10.0$ months, $\mathrm{p}<0.001$, MannWhitney $U$ test). The saliva and serology results were used to compare the prevalence of HHV- 6 and HHV-7 in the two age groups, 0 to 12 months (24 children) and 13 to 24 months (20 children). The prevalence of HHV-6 was significantly greater than that of HHV-7 in the younger group, as determined by both saliva ( $p$ $=0.03)$ and serostatus $(\mathrm{p}=0.006)$, and in the older group by serology alone $\left(\mathrm{p}=0.01 ; \chi^{2}\right.$ test for all).

HHV-6 VIRAL LOADS IN PBMC: ASSOCIATION WITH PRIMARY INFECTION

HHV-6 viral loads were determined in qualitatively PCR positive PBMC and the results are shown in table 2 . Two children (one case, one control) were below the threshold of accurate quantification (data not shown). Three children (Nos 1, 15, and 25) were HHV-6 positive in blood, but PCR negative in saliva, suggesting primary HHV-6 infection. The viral loads in these three children were significantly higher (median 24213 genomes $/ 10^{6}$ PBMC, range 20816 to 320839 ) compared to the other quantifiable DNA-aemic children (median 1606 genomes $/ 10^{6} \mathrm{PBMC}$, range 318 to 8756 ; $\mathrm{p}<0.01$, Mann-Whitney U test). HHV-6 DNA was detected in the serum of two of the three children in the primary infection group and one child was weakly seropositive. Two of the three children with primary infection presented with fever and diarrhoea, whereas the third presented with a febrile fit and inflamed ear drum, and with non-bacterial pyuria. A cerebrospinal fluid sample from this child was acellular and negative for HHV-6 DNA by PCR. No other pathogens were associated as a cause of symptoms in these three children and their temperatures at presentation were similar to those of other cases.

HHV-7 VIRAL LOADS IN PBMC: ASSOCIATION WITH PRIMARY INFECTION

HHV-7 viral loads in children who were qualitatively DNA-aemic are shown in table 3 . Three children (Nos 12, 14, and 30) were PCR positive in blood, but negative in saliva. These three children with presumed primary HHV-7 infection had significantly increased viral loads (median 6040000 genomes $/ 10^{6} \mathrm{PBMC}$, range 3366000 to 77700000 ) compared to the other HHV-7 DNA-aemic children (median

Table 1 Prevalence of HHV-6 and HHV-7 in febrile infants and controls

\begin{tabular}{|c|c|c|c|c|c|c|}
\hline \multirow[b]{2}{*}{ Laboratory assay } & \multicolumn{3}{|l|}{$H H V-6$} & \multicolumn{3}{|l|}{$H H V-7$} \\
\hline & Cases & Controls & $p^{*}$ & Cases & Controls & $p^{*}$ \\
\hline \multicolumn{7}{|l|}{ Qualitative PCR } \\
\hline PBMC & $12 / 33(36.4 \%)$ & $2 / 7(28.6 \%)$ & 1.0 & $6 / 33(18.2 \%)$ & $1 / 7(14.3 \%)$ & 1.0 \\
\hline Saliva & $22 / 41(53.7 \%)$ & $2 / 5(40.0 \%)$ & 0.91 & $14 / 41(34.1 \%)$ & $1 / 5(20.0 \%)$ & 0.94 \\
\hline Seropositivity & $29 / 41(70.7 \%)$ & $4 / 7(57.1 \%)$ & 0.76 & $13 / 41(31.7 \%)$ & $3 / 7(42.9 \%)$ & 0.86 \\
\hline
\end{tabular}

PBMC $=$ peripheral blood mononuclear cells $\mathrm{PCR}=$ polymerase chain reaction

* Statistical analyses of prevalences in cases compared to controls by Fisher's exact test. 
Table 2 HHV-6 PCR analysis: association with primary infection

\begin{tabular}{|c|c|c|c|c|c|}
\hline $\begin{array}{l}\text { Study No } \\
\text { (age in months) }\end{array}$ & $\begin{array}{l}\text { HHV-6 viral load } \\
\text { (genomes } / 10^{6} \\
\text { PBMC) }\end{array}$ & Saliva PCR & Serum PCR & Serostatus & $\begin{array}{l}\text { Case/control } \\
\text { status }\end{array}$ \\
\hline$\star 25(9)$ & 320839 & - & - & - & Case \\
\hline *15(8) & 24213 & - & + & + & Case \\
\hline${ }^{\star} 1(7)$ & 20816 & - & + & - & Case \\
\hline 19 (13) & 8756 & + & - & + & Case \\
\hline $4(7)$ & 3704 & + & - & + & Case \\
\hline $48(15)$ & 2365 & nst & - & + & Control \\
\hline 7 (14) & 2072 & + & - & + & Case \\
\hline $35(14)$ & 1606 & + & - & + & Case \\
\hline $27(10)$ & 1430 & + & - & + & Case \\
\hline $28(15)$ & 1267 & + & - & + & Case \\
\hline $30(21)$ & 453 & + & - & + & Case \\
\hline $42(10)$ & 318 & + & - & + & Case \\
\hline
\end{tabular}

*Primary infections; $\nmid$ ns $=$ no sample.

PBMC = peripheral blood mononuclear cells; $\mathrm{PCR}=$ polymerase chain reaction

Table 3 HHV-7 PCR analysis: association with primary infection

\begin{tabular}{llllll}
\hline $\begin{array}{l}\text { Study No } \\
\text { (age in months) }\end{array}$ & $\begin{array}{l}\text { HHV-7 viral load } \\
\text { (genomes/10 } \\
\text { PBMC) }\end{array}$ & Saliva PCR & Serum PCR & Serostatus & $\begin{array}{l}\text { Case/control } \\
\text { status }\end{array}$ \\
\hline$\star 14(9)$ & 77700000 & - & + & - & Case \\
$\star 30(21)$ & 6040000 & - & - & + & Case \\
$\star 12(13)$ & 3366000 & - & - & - & Case \\
$24(16)$ & 17609 & + & - & + & Case \\
$7(14)$ & 5825 & + & - & + & Case \\
$45(31)$ & 3254 & + & - & + & Control \\
$8(16)$ & 1668 & + & - & + & Case
\end{tabular}

${ }^{\star}$ Primary infections

PBMC = peripheral blood mononuclear cells; $\mathrm{PCR}=$ polymerase chain reaction.

7089 genomes $/ 10^{6} \mathrm{PBMC}$, range 1668 to 17 609; $\mathrm{p}<0.05$; Mann-Whitney U test). Two of the children with primary HHV-7 infection were seronegative, the other was weakly seropositive. In addition child No 14 was also serum PCR positive for HHV-7 DNA. All three children with HHV-7 infection presented with febrile fits, two with respiratory tract symptoms, and one with conjunctivitis. Cerebrospinal fluid samples were not available for analysis. No other pathogens were identified from urine or blood cultures, and the temperatures on presentation of these three children were similar to those of the other cases.

BLOOD CELL COUNTS IN PRIMARY HHV-6 OR HHV-7 INFECTION

The combined primary HHV-6 and HHV-7 cases (six in total) had significantly lower mean white cell counts $\left(7.9 v 16.7 \times 10^{9} / 1 ; \mathrm{p}=0.01\right.$; Student's $t$ test) and neutrophil counts (4.0 v $\left.10.7 \times 10^{9} / 1 ; \mathrm{p}<0.05\right)$ than non-primary infection cases. Although there was a trend for lower total white cell, lymphocyte, and neutrophil counts in the primary HHV-6 or HHV-7 infection groups alone compared to the other cases, these differences were not significant (data not shown).

\section{Discussion}

In this report we describe the use of both qualitative and quantitative PCR to identify primary HHV-6 and HHV-7 infections in febrile infants, based on the differential detection of viral DNA in PBMC, but not in saliva. This diagnostic rationale is based on the reported temporal delay in the detection of HHV-6 or HHV-7 in saliva in comparison with the viraemic/DNA-aemic phase following primary infection. ${ }^{11}{ }^{12}$ On this evidence we identi- fied primary HHV-6 and HHV-7 infections in six of 41 febrile infants (three HHV-6, $7.3 \%$; three HHV-7, $7.3 \%$ ), but not in seven nonfebrile controls.

Using QPCR, the HHV-6 and HHV-7 viral loads in PBMC were highest in children who were saliva PCR negative, most likely reflecting active replication in blood during the acute phase of disease and before excretion of virus in the oral cavity. It remains possible that slightly increased viral loads, such as found in child No 19 (table 2), which occur in the context of a PCR positive saliva, represent either reactivation, reinfection, or a slightly later phase of primary infection. However, the association of high viral load in PBMC and a PCR negative saliva suggests that the analysis of a combination of blood and saliva collected in the acute phase of disease could identify children undergoing primary infection.

We detected viral DNA by PCR in serum from two of the three children with putative primary HHV-6 infection and one of the three with HHV-7 infection. Serum or plasma PCR has been proposed as a suitable method to detect active HHV-6 replication. ${ }^{9}{ }^{10}$ However, a potential drawback is the apparent delay of detectable HHV-6 DNA in serum from children with exanthem subitum. ${ }^{9}$ A case report of a child with HHV-7 confirmed exanthem subitum did not detect viral DNA in plasma by nested HHV-7 PCR. ${ }^{12}$ In our study, $50 \%$ of the primary infections would have remained undetected based on serum PCR alone.

Serological analysis of a single serum or plasma sample is problematic in the diagnoses of HHV-6 and HHV-7 infections in young children at acute presentation. In this study, one child each with primary HHV-6 or HHV-7 infection was weakly seropositive. Given the young age of the children investigated, the possible confounding effect of maternally derived antibodies has to be considered. One study used the presence of low avidity antibody to HHV-6 in febrile children as a marker for recent infection. ${ }^{17}$ However, serum samples collected within the acute phase of suspected HHV-6 infection were often seronegative. For demonstration of seroconversion, the collection of paired sera from young children is impractical. These difficulties highlight the advantages of PCR analysis where only samples taken in the acute phase of illness are available.

Seroepidemiological studies have shown that HHV-6 infection occurs earlier in life compared to HHV-7, ${ }^{13}$ although not consistently so. ${ }^{2}$ In our study, HHV-6 seroprevalences were significantly higher than those of HHV-7 in two age groups (0 to 12 months, 13 to 24 months). However, by saliva PCR status, the prevalence of HHV-6 was significantly greater in the younger group only. Detection of viral DNA in saliva represents previous infection. In addition to the presence of maternal antibodies, the type of assay/antigen source or potential antigenic cross reactivity between HHV-6 and HHV-7 could affect rates of seropositivity. 
In summary, we have identified three infants with febrile convulsions associated with primary HHV-7 infection. These findings, taken together with previous reports of febrile convulsions and acute hemiplegia in infants with HHV-7 infection, ${ }^{78}$ highlight the need to consider HHV-7 as well as HHV-6 in the differential diagnosis of febrile illness in infants. Definitive laboratory diagnoses of HHV-7 and particularly HHV-6 infections have relied previously on virus isolation or seroconversion. The results of this study suggest that PCR, including QPCR, can be used to identify primary HHV-6 and HHV-7 infections with an appropriate combination of clinical specimens. In order to address the specificity and sensitivity of PCR diagnosis, larger numbers of febrile children and controls will need to be studied. The ability to diagnose infection by PCR during the acute phase of disease would facilitate clinical trials of antiviral agents with activity against either virus.

This work was funded by the National Institutes of Health, USA (grant number AI-33389), Smithkline Beecham, and GlaxoWellcome. We thank J Hoxie, the MRC AIDS Directed Programme Reagent Project, and the NIH NIAID AIDS Research and Reference Reagent Program (for supplying SUP-T1 cells).

1 Wyatt LS, Rodriguez WJ, Balachandran N, Frenkel N. Human herpesvirus 7: antigenic properties and prevalence in children and adults. 7 Virol 1991;65:6260-5.

2 Clark DA, Freeland JML, Mackie PLK, Jarrett RF, Onions DE. Prevalence of antibody to human herpesvirus 7 by age. I Infect Dis 1993;168:251-2.

3 Tanaka-Taya K, Kondo T, Mukai T, et al. Seroepidemiological study of human herpesvirus- 6 and -7 in children of different ages and detection of these two viruses in throat ferent ages and detection of these two viruses in throat
swabs by polymerase chain reaction. $\mathcal{F}$ Med Virol $1996 ; 48$ : swabs by
4 Hall CB, Long CE, Schnabel KC, et al. Human herpesvirus- 6 infection in children. A prospective study of complications and reactivation. N Engl f Med 1994;331: complicati 432 -8.

5 Yamanishi K, Okuno T, Shiraki K, et al. Identification of human herpesvirus- 6 as a causal agent for exanthem subitum. Lancet $1988 ; \mathbf{i}: 1065-7$

6 Tanaka K, Kondo T, Torigoe S, Okada S, Mukai T, Yamanishi K. Human herpesvirus 7: another causal agent for roseola (exanthem subitum). $\mathscr{7}$ Pediatr 1994;125:1-5.

7 Torigoe S, Kumamoto T, Koide W, Taya K, Yamanishi K. Clinical manifestations associated with human herpesvirus 7 infection. Arch Dis Child 1995;72:518-9.

8 Torigoe S, Koide W, Yamada M, Miyashiro E, Tanaka-Taya $\mathrm{K}$, Yamanishi K. Human herpesvirus 7 infection associated with central nervous system manifestations. F Pediatr 1996; 129:301-5.

9 Huang L-M, Kuo P-F, Lee C-Y, Chen J-Y, Liu M-Y, Yang C-S. Detection of human herpesvirus-6 DNA by polymerase chain reaction in serum or plasma. 7 Med Virol 1992;38:7-10.

10 Secchiero P, Carrigan DR, Asano Y, et al. Detection of human herpesvirus 6 in plasma of children with primary infection and immunosuppressed patients by polymerase chain reaction. F Infect Dis 1995;171:273-80.

11 Suga S, Yazaki T, Kajita Y, Ozaki T, Asano Y. Detection of human herpesvirus 6 DNAs in samples from several body sites of patients with exanthem subitum and their mothers by polymerase chain reaction. f Med Virol 1995;46:52-5.

12 Asano Y, Suga S, Yoshikawa T, Yazaki T, Uchikawa T. Clinical features and viral excretion in an infant with primary human herpesvirus 7 infection. Pediatrics 1995;95:187-90.

13 Wakefield AJ, Fox JD, Sawyerr AM, et al. Detection of herpesvirus DNA in the large intestine of patients with ulcerative colitis and Crohn's disease using the nested polymerase chain reaction. F Med Virol 1992;38:183-90.

14 Clark DA, Ait-Khaled M, Wheeler AC, et al. Quantification of human herpesvirus 6 in immunocompetent persons and post-mortem tissues from AIDS patients by PCR. 7 Gen Virol 1996;77:2271-5.

15 Kidd IM, Clark DA, Ait-Khaled M, Griffiths PD, Emery VC. Measurement of human herpesvirus 7 load in peripheral blood and saliva of healthy subjects by quantitative polymerase chain reaction. F Infect Dis 1996;174:396-401.

16 Whitby D, Howard MR, Tenant-Flowers M, et al. Detection of Kaposi sarcoma associated herpesvirus in peripheral lood of HIV-infected individuals and progression to Kaposi's sarcoma. Lancet 1995;346:799-802.

17 Ward KN, Gray JJ. Primary human herpesvirus-6 infection is frequently overlooked as a cause of febrile fits in young children. F Med Virol 1994;42:119-23. 